\title{
Representasi Anak pada Film Perang Analisis Semiotika pada Film Life is Beatiful dan The Boy in The Stripped Pajamas
}

\author{
Children Representation on War Film \\ Semiotic Analysis of film Life is Beautiful and \\ The Boy in The Striped Pajamas
}

\author{
ANDALUSIA NENENG PERMATASARI \\ Fakultas Ilmu Komunikasi, Universitas Islam Bandung \\ JIn. Tamansari No. 1 Bandung, Indonesia. \\ Email: andalusianp@gmail.com
}

\begin{abstract}
This study aims to explain the representation of children in war-theme movies, entitled: "Life is Beautiful" and "The Boy in The Striped of Pajamas". Both of movies have the same story setting, that is when NAZI dominate Europe. The main characters from those movies are children aged 6 and 7 years old. At that age, children are at a pra-operational phase on cognitive development. With qualitative approach and semiotic analysis, this study presents the early childhood's construction of meaning about the conditions of war. The results of this study show that the children characters in this both film are represented to be the individuals that have the right to get a better life.
\end{abstract}

Keywords: Children, Pra-Operational Phase, Representation, War Film, and Semiotics.

\begin{abstract}
Abstrak
Penelitian ini bertujuan untuk menjelaskan representasi anak pada film perang. Film yang dianalisis adalah "Life is Beautiful" dan "The Boy in The Striped of Pajamas". Kedua film tersebut memiliki latar cerita yang sama, yaitu saat NAZI berkuasa di Eropa. Selain itu, kedua film pun memiliki tokoh yang sama, yaitu anak usia dini yang berumur 6 dan 7 tahun. Anak-anak pada usia itu berada pada fase pra-operasional dalam perkembangan kognitif. Dengan pendekatan kualitatif dan analisis semiotik, penelitian ini dapat menggambarkan secara mendalam konstruksi makna yang dilakukan anak usia dini mengenai kondisi perang. Hasil penelitian ini adalah anak direpresentasikan oleh kedua film sebagai penerima hak untuk kehidupan yang lebih baik dari kondisi perang.
\end{abstract}

Kata Kunci: Anak, Fase Pra-Operasional, Representasi, Film Perang, dan Semiotik

\section{Pendahuluan}

Kisah mengenai anak dan perang memang menarik untuk diangkat dalam sebuah karya seni. Sejak tahun 1948 sampai tahun 2008, tercatat ada sepuluh film yang mengangkat tema suasana, reaksi, dan dampak perang terhadap perkembangan fisik dan psikis seorang anak.

Tahun 1948, muncul film Bicyle Thieves yang berlatarkan perang dunia ke II di Italia. Tahun 1959 muncul film hasil adaptasi dari buku yang berjudul sama, yaitu The Diary of Anne Frank. Kisah yang diperoleh dari buku harian seorang anak perempuan di Belanda yang berlatar kisah fasisme Nazi.

Selanjutnya, tahun 1979 dan 1985 tayang film Come and See dan The Tin Drum yang berlatar perang dunia II di Belarusia dan Polandia. Tahun 1987, tercatat ada dua film mengenai perang dan anak, yaitu Au Revoir Les Enfant dan Empire of The Sun. Berbeda dengan film-film sebelumnya, latar yang diangkat oleh film Empire of The Sun adalah masa invansi Shanghai oleh Jepang.

Di awal tahun 90-an, tepatnya tahun 1990, film Europa Europa ditayangkan. Film tersebut mengangkat cerita seorang anak Jerman yang sejak kecil sudah masuk ke 
barisan Hitler Youth. Lalu, tahun 1997 tayang film yang cukup fenomenal dengan meraih berbagai penghargaan di ajang Oscar, yaitu Life is Beautiful.

Tahun 2007, anak dan perang kembali diangkat melalui film adaptasi dari novel karya Khaled Hosseini yang terbit tahun 2003, yaitu Kite Runner. Sama hal dengan novelnya, film ini berlatar gejolak sosial yang terjadi di Afganistan akibat intervensi Soviet. Satu tahun kemudian, tahun 2008, film The Boy in The Striped Pajamas ditayangkan. Film ini meski tidak menunjukkan kerasnya perang di lapangan, namun mampu memperlihatkan efek dan ekses perang pada psikologis seorang anak.

Kesepuluh film yang disebutkan tersebut menunjukkan kerasnya perang dan bagaimana kondisi serta reaksi anakanak yang hidup pada zaman perang. Dari kesepuluh film tersebut, dua film yang menjadikan anak pada masa pra-operasional sebagai fokus cerita, yaitu Life is Beautiful (1997) dan The Boy in The Striped Pajamas (2008). Anak yang menjadi tokoh utama pada kedua film tersebut berumur dalam kisaran 5-7 tahun.

Anak dan perang bukanlah hal yang baru untuk dibahas dan diperbincangkan. Dalam konteks peperangan, mayoritas yang menjadi korban selain perempuan adalah anak-anak.

Pada perang Irak, perang dan konflik menyebabkan korban anak-anak sebanyak 4,5 juta anak (Iraq's Independent for Administration and Civil Society Studies, 2008). Korban di sini bukan saja anak sebagai korban jiwa, tetapi korban secara psikologis dan materi juga. Contohnya, satu dari tiga anak menjadi yatim piatu, jumlah pekerja di bawah umur meningkat, dan ratusan ribu anak-anak menjadi gelandangan.

Penderitaan anak-anak dalam konflik atau perang juga dicatat oleh Unesco. Pada tahun 2015, Unesco mengeluarkan data kurang lebih empat belas juta anak menderita akibat perang Suriah. Penderitaan itu berupa kehilangan kesempatan pendidikan, kurang gizi, dan dikelilingi suasana kekerasan (Tirto. id, 2016).

Semua yang terjadi pada anak-anak di daerah konflik atau perang tentu saja bertentang dengan hak anak yang dicetuskan pada Konferensi Hak Anak. Keempat hak anak yang terberangus akibat perang adalah (1) hak kelangsungan hidup, seperti hak untuk memeroleh layanan kesehatan; (2) hak berkembang, seperti pemberian gizi dan pendidikan serta olah budaya agar anak tumbuh sebagai manusia dewasa yang beridentitas dan bermartabat; (3) hak memeroleh perlindungan dari diskriminasi dan tindak kejahatan; dan (4) hak untuk berpartisipasi dalam berbagai keputusan yang menyangkut hidupnya (Hartiningsih dalam Lilis Ch, 2014 ).

Ada beberapa penelitian yang mengkaji kaitan anak, film, dan perang. Salah satunya adalah penelitian Permatasari (2015) yang berjudul "Pemaknaan Tanda pada Anak Usia Dini". Penelitian tersebut memperlihatkan proses pemaknaan seorang anak berusia tujuh tahun pada segala hal yang ditemuinya dalam film The Boy in The Striped Pajamas, yaitu pemaknaan pada baju piyama bergaris.

Pada penelitian tersebut, Permatasari (2015) memeroleh temuan bahwa anak pada tahap pra-operasional memaknai sesuatu sebagaimana dia ingin memaknainya. Tokoh anak pada film The Boy in The Striped Pajamas memaknai piyama bergaris sebagai seragam bermain sebagaimana garis pada komidi putar dan permen yang merupakan kesukaan anakanak. Padahal baju bergaris yang terdapat pada film tersebut adalah baju penjara untuk kaum Yahudi pada masa kekuasaan NAZI. Berdasarkan hasil penelitiannya juga, Permatasari (2015) menyatakan perang dapat mengikis kepolosan dan keceriaan seorang anak. Akibat pemaknaan anak berusia tujuh tahun pada baju piyama bergaris itulah, petaka pun datang.

Ada juga penelitian yang dilakukan Maluda (2014) mengenai representasi kekerasan pada anak. Maluda menggunakan analisis semiotik untuk mengungkap bagaimana kekerasan pada anak direpresentasikan pada film Alangkah Lucunya Negeri Ini. Hasil penelitiannya menunjukkan bahwa kekerasan direpresentasikan pada film tersebut dengan tindakan seperti memukul, menampar, menyepelekan, dan lain-lain. Tidak hanya tindakan, kekerasan pada anak direpresentasikan dengan perkataan seperti memaki, menghardik, dan membentak.

Tidak banyak yang melakukan kajian terhadap posisi, kondisi, dan reaksi anak-anak di daerah perang yang diceritakan para sineas dalam film-film. Oleh karena itu, penelitian ini bertujuan untuk menguak bagaimana film-film berlatar perang merepresentasikan anak-anak yang hidup di daerah konflik atau masa peperangan. Film yang menjadi objek 
kajian adalah film Life is Beautiful (1997) dan The Boy in The Striped Pajamas (2008). Kedua film ini dipilih karena kesamaan tokoh anak yang sama-sama berada pada fase praoperasional, yaitu usia $2-7$ tahun.

Film Life is Beautiful dan The Boy in The Striped Pajamas sama-sama berlatar masa kekuasaan Nazi di Eropa. Life is Beautiful karya Roberto Benigni mengambil suasana pendudukan Nazi di Italia sedangkan The Boy in The Striped Pajamas mengambil suasana di Jerman.

Life is Beautiful mengisahkan tokoh bernama Guido, orang Yahudi yang ceria dan humoris, memiliki seorang anak dan istri. Suatu hari, mereka sekeluarga ditangkap oleh tentara NAZI. Sejak masa penangkapan itulah, Guido berusaha menciptakan suasana dan nuansa bermain pada anaknya walau sedang ada di kamp konsentrasi NAZI. Guido mengatakan pada anaknya bahwa ini hanya permainan perang-perangan untuk memperoleh hadiah tank mainan. Sang anak pun tidak merasa ketakutan dan tidak pernah merasa sedang ada di sebuah kamp konsentrasi.

Adapun film The Boy in The Striped Pajamas karya Mark Heman mengisahkan seorang anak lelaki bernama Bruno yang merasa bosan di rumah barunya. Bruno anak panglima NAZI yang baru saja dipindahtugaskan untuk mengomando kamp konsentrasi di suatu pedesaan. Bruno yang kesepian akhirnya memeroleh teman bernama Schmuel, yaitu seorang anak keturunan Yahudi yang menempati kamp konsentrasi yang dikomando oleh ayah Bruno. Pertemanannya dengan Schmuel membawa Bruno pada petualangannya untuk memahami baju bergaris yang selalu dikenakan Schmuel, bangunan berjeruji tempat Schmuel tinggal, dan semuanya itu dipahami dengan cara pandangnya sendiri sebagai anak berusia tujuh tahun.

Kedua film tersebut sama-sama menyoroti posisi anak-anak dalam kemelut perang. Latar konflik perang kedua film tersebut pun sama, yaitu masa konflik antara NAZI dan kaum Yahudi. Tokoh utama dari kedua film tersebut pun sama-sama berada dalam fase kognitif pra-operasional. Oleh karena itulah, penulis memilih dua film tersebut untuk dianalisis mengenai representasi anak pada film perang. Oleh karena itu, tujuan penelitian ini adalah menjelaskan sosok anakanak direpresentasikan dan diposisikan dalam sebuah film bergenre war film (film perang).

\section{Metodologi Penelitian}

Penelitian ini menggunakan pendekatan kualitatif dengan analisis semiotika. Analisis semiotika dilakukan untuk menemukan dan menginterpretasi tanda yang pada film Life is Beautiful dan The Boy in The Striped Pajamas. Tanda-tanda pada kedua film tersebut dianalisis untuk menjelaskan representasi anak-anak pada film bergenre war film. Adapun teknik analisis yang dilakukan pada penelitian ini adalah (1) menentukan pola konstruksi pemaknaan sosok anak pada kondisi perang yang ditampilkan masingmasing dari film Life is Beautiful dan The Boy in The Striped Pajamas; (2) setelah menemukan konstruksi makna anak pada kondisi perang lalu dibandingkan antara kedua film tersebut untuk memperoleh pemaknaan yang sama; (3) Konstruksi makna yang sama akan membangun representasi anak pada film dengan latar kondisi perang.

\section{Pembahasan}

Danesi (2012) mengatakan representasi adalah penggunaan tanda (suara/bunyi, gambar, dan lain-lain) untuk menghubungkan, memproduksi, menggambarkan, memotret sesuatu yang dilihat, dibayangkan, dirasakan dalam bentuk fisik tertentu. Adapun tanda itu sendiri adalah segala sesuatu (warna, isyarat, kedipan mata, objek, rumus matematika, dan lain-lain) yang merepresentasikan sesuatu yang lain selain dirinya (Danesi, 2012).

Selaras dengan Giles dan Middleton (1999) yang merumuskan representasi atau to represent menjadi tiga macam. Pertama, to stand in for, seperti bendera negara di acara olimpiade. Bendera tersebut merepresentasikan negara tersebut mengikuti olimpiade. Kedua, to speak or act on behalf of, seperti presiden atau seorang kepala negara yang menyampaikan sebuah kebijakan internasional. Penyampaian yang dilakukan seorang presiden merepresentasikan kehendak dan keputusan dari suatu negara. Ketiga, to re-present, seperti film dokumenter yang memotret peristiwa-peristiwa yang pernah terjadi. Film dokumenter tersebut menggambarkan kembali hal-hal yang pernah terjadi atau pernah ada.

Hal yang dirujuk oleh sebuah tanda disebut referen atau petanda, baik yang konkret ataupun abstrak. Dengan adanya tanda dan referen, kita langsung merujuk pada sebuah benda atau gagasan walaupun tidak tampak secara fisik. Misalnya, jika kita 
mendengar kata "perang", muncul citraan dalam benak kita. Citraan itulah yang disebut dengan konsep.

Ada yang mengatakan bahwa ketika mendengar kata "perang" maka yang muncul di benak adalah pertikaian. Jika minta dispesifikkan lagi, maka "perang" adalah pertikaian untuk sebuah kepentingan. Lebih spesifik lagi adalah pertikaian antarnegara, antargolongan, ataupun antarkelompok untuk sebuah kepentingan yang seringkali memakan korban.

Konsep atau citraan sangat berkaitan dengan budaya dan pengalaman personal masing-masing individu. Oleh karena itu, Danesi (2012) menyimpulkan bahwa tanda dapat didefinisikan sebagai sesuatu yang merepresentasikan seseorang atau sesuatu yang lain dalam kapasitas atau pandangan tertentu.

Representasi memang sangat erat kaitannya dengan konsep dalam pikiran dan konsep dalam bahasa (Hall, 2003). Konsep dari suatu hal yang ada dalam pikiran kita menyebabkan kita memaknai konsep tersebut. Untuk mengomunikasikan pemaknaan, bahasa digunakan sebagai sarananya.

Bettetini (1973) mengatakan bahwa film itu dibangun oleh berbagai elemen atau sumber-sumber yang dapat memancing penonton untuk berasumsi, membuat perkiraan, atau berhipotesis. Asumsi, perkiraan, dan hipotesis tersebut diciptakan berdasarkan pengetahuan dan wawasan masing-masing penonton.

Film memiliki kekuatan besar bagi dari segi estetika karena menjajarkan dialog, musik, pemandangan, dan tindakan bersamasama secara visual dan naratif (Danesi, 2012). Sebuah film dapat menunjukkan bagaimana suatu hal dikonstruksi dan dibuat untuk membuat sebuah representasi yang diinginkan.

Film Life is Beautiful dan The Boy in The Striped Pajamas mengonstruksi citra perang dengan meminjam sudut pandang dari anak. Dari kedua film tersebut ada salah satu kesamaan, yaitu pilihan orang tua untuk tidak berterus terang terhadap kondisi perang. Perhatikan tabel di bawah ini.

Tabel 1. Sikap Orang Tua Menjelaskan Perang

\begin{tabular}{|l|l|l|}
\hline \multicolumn{1}{|c|}{$\begin{array}{c}\text { Sikap orang tua } \\
\text { menjelaskan perang }\end{array}$} & \multicolumn{1}{|c|}{ Adegan dalam film } & \multicolumn{1}{c|}{ Konstruksi Makna } \\
\hline Life is Beautiful & $\begin{array}{l}\text { Guido, tokoh ayah, mengatakan pada } \\
\text { anaknya bahwa ini adalah permainan } \\
\text { sementara untuk memperoleh hadiah } \\
\text { berupa tank mainan. }\end{array}$ & $\begin{array}{l}\text { Orang tua memilih untuk tidak } \\
\text { terus terang mengenai keadaan dan } \\
\text { kondisi perang pada anaknya. }\end{array}$ \\
$\begin{array}{l}\text { The Boy in The Striped } \\
\text { Pajamas }\end{array}$ & $\begin{array}{l}\text { Ayah Bruno sebagai komandan Nazi } \\
\text { mengatakan bahwa Nazi berusaha } \\
\text { melindungi dan membuat dunia lebih } \\
\text { baik dan indah. }\end{array}$ & \\
\hline
\end{tabular}

Berdasarkan tabel di atas, kedua film mengambil sudut pandang yang sama mengenai sikap orang tua dalam menjelaskan perang pada anak-anaknya. Hal tersebut disebabkan oleh keyakinan tiap orang tua bahwa anak-anak hanya boleh melihat dan mendengar hal yang baik.

Perang didefinisikan oleh Clausewitz (dalam Wardoyo, 2015) sebagai kondisi yang memberlakukan penggunaan kekerasan pada musuh untuk mencapai tujuan tertentu. Orang tua tentu sudah memahami kondisi dan konsekuensi dari perang. Adanya kekerasan, korban, dan keterberangusan baik harta ataupun kehidupan itulah yang ingin ditutupi masing-masing tokoh ayah dalam film Life is Beautiful dan The Boy in The Striped Pajamas walaupun tokoh ayah dari masing-masing film berada pada posisi berbeda.

Tokoh ayah pada film Life is Beautiful adalah seorang narapidana bagi pihak NAZI. Adapun tokoh ayah dalam film The Boy in The Striped Pajamas merupakan seorang komandan NAZI. Walaupun berbeda posisi dan keadaan, namun memiliki kebijakan yang sama untuk anak. Kebijakannya, yaitu dunia anak adalah dunia bermain yang identik dengan keriangan dan kebahagiaan. Bagaimanapun kondisi dan situasi saat perang, seorang anak harus mendapatkan 
haknya untuk riang dan gembira. Kesamaan kebijakan tersebut menunjukkan bahwa konstruksi makna yang dibangun tentang sikap orang tua untuk menjelaskan kondisi perang pada film Life is Beautiful dan The Boy in The Striped Pajamas memiliki kesamaan.
Selain itu, kesamaan kedua adalah pemaknaan bahwa kamp konsentrasi atau tahanan tentara Jerman adalah tempat bermain. Perhatikan tabel di bawah ini!

Tabel 2. Kamp Konsentrasi adalah Tempat Bermain

\begin{tabular}{|l|l|l|}
\hline \multicolumn{1}{|c|}{$\begin{array}{c}\text { Kamp Konsentrasi adalah } \\
\text { Tempat Bermain }\end{array}$} & \multicolumn{1}{|c|}{ Adegan dalam film } & Konstruksi Makna \\
\hline Life is Beautiful & $\begin{array}{l}\text { Joshua (tokoh anak dalam film } \\
\text { ini) menganggap bahwa kamp } \\
\text { konsentrasi/ tahanan tentara NAZI } \\
\text { adalah tempat bermain adu angka dan } \\
\text { petak umpet. }\end{array}$ & $\begin{array}{l}\text { Dunia anak usia dini } \\
\text { adalah dunia bermain. }\end{array}$ \\
The Boy in The Striped Pajamas & $\begin{array}{l}\text { Bruno bertanya pada Schmuel kenapa } \\
\text { dia tidak bisa bermain di tempat } \\
\text { Schmuel yang berpagar duri. }\end{array}$ & \\
\hline
\end{tabular}

Wiyanto dan Mustakim (2012) mengatakan salah satu karakteristik anak usia dini adalah senang dengan nyanyian dan permainan. Tokoh anak dalam kedua film tersebut masih termasuk anak usia dini. Joshua berumur 5 tahun dan Bruno berumur 7 tahun. Umur 5-7 tahun dalam perkembangan kognitif (cognitive development) berada pada fase pra-operasional.

Ciri seorang manusia berada pada fase pra-operasional adalah memusatkan segala sesuatu pada dirinya (egosentris). Egosentris inilah yang menyebabkan seorang manusia pada fase pra-operasional memaknai segala sesuatu sebagaimana yang dikehendakinya sendiri. Apa-apa yang dimaknai tidak akan jauh dari kehidupan sehari-hari yang dialaminya.

Contohnya saja tokoh anak-anak pada film Life is Beautiful dan The Boy in The Striped Pajamas. Kedua film tersebut berusaha membangun konstruksi makna berdasarkan karakteristik anak usia dini yang berada pada fase pra-operasional tersebut. Karena fokus anak usia dini masih pada permainan, maka tidaklah heran jika tokoh Joshua pada film Life is Beautiful dan tokoh Bruno pada film The Boy in The Striped Pajamas menganggap bahwa kamp konsentrasi adalah tempat bermain.

Konsep kamp konsentrasi sebagai tempat bermain pada film Life is Beautiful ditunjukkan dengan sikap tokoh Joshua yang menganggap kamp konsentrasi tempat bermain untuk petak umpet dan adu angka. Itu dilakukan tokoh Joshua dengan ayahnya. Bahkan, ketika ada adegan pemeriksaan oleh kepala kamp, Joshua menganggap jika dia bersembunyi dan tidak dapat ditemukan oleh kepala kamp berarti dia menang. Oleh karena itu, setiap kali kepala kamp datang memeriksa setiap ruangan, dia akan berusaha keras untuk bersembunyi.

Konsep tempat bermain yang sangat berkaitan erat dengan anak pun ditunjukkan oleh film The Boy in The Striped Pajamas. Pada film tersebut, Bruno menganggap bahwa jeruji besi berlistrik tempat Schmuel tinggal adalah tempat bermain. Bruno bahkan bertanya pada Schmuel kenapa dia tidak bisa masuk bermain di dalamnya.

Kedua kesamaan antara kedua film tersebut pun memiliki penyebab yang sama. Tokoh Joshua pada film Life is Beautiful menganggap kamp konsentrasi sebagai tempat bermain karena ayahnya memperkenalkan dan menekankan padanya bahwa kamp konsentrasi sama halnya dengan tempat bermain dia seperti biasa. Para tahanan adalah teman setim bermain. Para sipir dan prajurit NAZI adalah tim lawan. Begitu pula dengan tokoh ayah pada film The Boy in The Striped Pajamas mengatakan pada Bruno bahwa kamp konsentrasi itu tempat yang indah. Ada taman bermain dan fasilitas yang menyenangkan. Hal tersebut dimaksudkan agar Bruno meyakini bahwa ayahnya yang panglima NAZI melakukan pekerjaan yang baik untuk kemanusiaan, walau kenyataannya sebaliknya.

Perbedaan keadaan antara tokoh Joshua pada Life is Beautiful dan Bruno pada The Boy in The Striped Pajamas memperkuat 
konstruksi makna yang hendak dibangun. Meskipun posisi dan keadaan mereka berbeda, pemaknaan mereka pada kamp konsentrasi serupa, yaitu tempat bermain.
Kesamaan ketiga adalah pemaknaan lawan tidak selamanya. Dengan kata lain, seorang anak tidak mengenal konsep musuh.

Tabel 3. Tidak Ada Lawan/Musuh

\begin{tabular}{|l|l|l|}
\hline $\begin{array}{l}\text { Tidak Ada Lawan/ } \\
\text { Musuh }\end{array}$ & \multicolumn{1}{|c|}{ Adegan dalam film } & \multicolumn{1}{c|}{$\begin{array}{c}\text { Konstruksi } \\
\text { Makna }\end{array}$} \\
\hline Life is Beautiful & $\begin{array}{l}\text { Joshua menganggap anak-anak Jerman yang ada di sekitar } \\
\text { kamp konsentrasi adalah teman bermainnya walaupun bahasa } \\
\text { yang digunakan tidak dipahami olehnya. }\end{array}$ & $\begin{array}{l}\text { Anak usia dini } \\
\text { begitu tertarik } \\
\text { pada teman dan } \\
\text { hubungan erat/ } \\
\text { intens dengan }\end{array}$ \\
$\begin{array}{l}\text { The Boy in The } \\
\text { Striped Pajamas }\end{array}$ & $\begin{array}{l}\text { Bruno sangat senang bisa menemukan anak seusianya di } \\
\text { kamp konsentrasi. Begitupula Schmuel sangat senang bisa } \\
\text { bertemu Bruno meski tahu Bruno anak Jerman. }\end{array}$ & teman. \\
\hline
\end{tabular}

Anak usia dini sangat berminat terhadap teman dan telah mampu menunjukkan hubungan dan kerja sama intens dengan teman-temannya (Wiyanto dan Mustakim, 2012). Minat terhadap teman ditunjukkan melalui tokoh Joshua dan Bruno.

Joshua, tokoh anak pada film Life is Beautiful, memaknai kamp konsentrasi NAZI sebagai tempat bemain. Misalnya, saat bertemu anak-anak Jerman yang bermain di sekitar kamp konsentrasi tanpa ragu dan takut Joshua menghampiri dan mengajak bermain. Hal tersebut menunjukkan, seorang anak mengonsep keadaan konflik belum sampai pada kekerasan dan musuh.

Adapun tokoh anak pada film The Boy in The Striped Pajamas yang bernama Bruno sangat bahagia mendapati seorang anak seusianya di daerah tempat tinggal yang baru. Walaupun anak tersebut berada di balik besi-besi listrik kamp konsentrasi, penuh luka, dan memakai baju tahanan, Bruno tetap menganggap bahwa anak itu adalah teman bermain. Bruno bahkan berbagi makanan, cerita, dan bermain bersama. Mereka tidak mempermasalahkan asal usul dan latar belakang keduanya yang sangat berbeda.

Dari penjelasan di atas dapat dipahami bahwa konstruksi makna yang coba disuguhkan adalah anak usia dini tidak pernah mengenal musuh, apalagi lawan selamanya. Minat yang begitu besar terhadap teman dan keinginan berhubungan yang baik dengan teman menjadi dasar kenapa anak usia dini tidak mengenal konsep musuh atau lawan.

Selanjutnya, kesamaan keempat adalah tokoh anak memaknai segala sesuatu seperti apa yang tampak atau berdasarkan apa yang dia inginkan. Perhatikan tabel di bawah ini!

Tabel 4. Pemaknaan yang Egosentris

\begin{tabular}{|c|l|l|}
\hline $\begin{array}{c}\text { Pemaknaan } \\
\text { yang Egosentris }\end{array}$ & \multicolumn{1}{|c|}{ Adegan dalam film } & Konstruksi Makna \\
\hline Life is Beautiful & $\begin{array}{l}\text { Ada sebuah kotak besi di sekitar kamp konsentrasi yang } \\
\text { Joshua anggap sebagai tempat bersembunyi paling sulit } \\
\text { ditemukan saat bermain petak umpet. }\end{array}$ & $\begin{array}{l}\text { Dunia anak usia } \\
\text { dini adalah dunia } \\
\text { bermain. }\end{array}$ \\
$\begin{array}{l}\text { The Boy in The } \\
\text { Striped Pajamas }\end{array}$ & $\begin{array}{l}\text { Baju bergaris dan nomor pada baju yang digunakan Schmuel } \\
\text { dimaknai Bruno sebagai seragam bermain dan nomor urutan } \\
\text { bermain. }\end{array}$ & \\
\hline
\end{tabular}

Egosentris dalam hal ini adalah anak usia dini ketika melakukan pemaknaan berpusat pada dirinya. Bagaimana mereka memaknai, itulah bagi mereka makna sebenarnya.

Wiyanto dan Mustakim (2012) menjelaskan bahwa karakteristik anak usia dini yang lain adalah pemahaman anak usia dini terhadap suatu konsep sangat bergantung kepada pengalaman-pengalaman langsung. Pengalaman Joshua pada film Life is Beautiful belum sampai pada konsep seperti apa dan bagaimana kamp konsentrasi. Oleh karena itu, tidaklah mengherankan apabila Joshua dalam mengeksplorasi segala hal di sekitar kamp konsentrasi sebagai sarana bermain. 
Sebagai contoh adalah kotak besi yang ada di lingkungan sekitar kamp konsentrasi dianggap Joshua sebagai tempat bersembunyi terbaik untuk permainan petak umpet. Hal itu selain karena diajarkan oleh ayahnya, Joshua pun telah membuktikan dengan bersembunyi di sana, semua orang hampir tidak menyadari keberadaannya. Bahkan, ketika ayahnya akan dihukum mati pun, Joshua bersembunyi di kotak besi itu agar dapat tidak ditemukan ayahnya yang menjadi lawan mainnya.

Karakteristik ini pun sesuai dengan tokoh Bruno pada film The Boy in The Striped Pajamas yang memaknai seragam bergaris dan nomor baju Schmuel sebagaimana apa yang dia tahu dan pernah dia temukan dalam hidupnya. Pemahaman Bruno adalah nomor sering muncul pada berbagai permainan. Seragam sangat identik dengan anak-anak, misalnya saat akan berwisata dari sekolah, anak-anak pasti diminta berseragam. Oleh karena itulah, tokoh Bruno menganggap baju tahanan yang dipakai Schmuel adalah baju bermain. Begitu pula nomor pada baju adalah nomor permainan.

Permatasari (2015) menyatakan bahwa pemaknaan Bruno tersebut baru sampai pada tahap secondness dalam segitiga standa Peirce, yaitu memaknai apa adanya dan apa yang ingin dia maknai. Dirinya adalah pusat segalanya.

Berdasarkan hal-hal tersebut, kontruksi makna yang dibangun adalah pemaknaan yang dilakukan oleh Joshua ataupun Bruno sangat egosentris. Piaget (dalam Keenan, 2009) menyebut pemaknaan yang egosentris merupakan karakteristik dari fase praoperasional pada perkembangan kognitif manusia. Hal senada juga dinyatakan oleh Martin dan Fabes (2009) bahwa anak usia dini telah mampu menggunakan simbol untuk merepresentasikan sesuatu. Walaupun penggunaan simbol tersebut berdasarkan pada apa yang dimaknainya sendiri.

Empat kesamaan konstruksi makna yang dibentuk oleh kedua film, baik Life is Beautiful dan The Boy in The Striped Pajamas, adalah merepresentasikan sosok seorang anak sebagai mahluk yang cukup hanya perlu tahu hal-hal yang baik dan menyenangkan. Bagaimanapun keras, bahaya, dan mengerikannya keadaan konflik atau perang, kedua film tersebut merusaha membangun sebuah makna bahwa anak-anak hanya perlu tahu bahwa dunia itu indah dan baik untuk ditinggali. Penjelasannya dapat dilihat pada bagan berikut.

\section{Bagan 1. Representasi Anak dalam Film Perang}

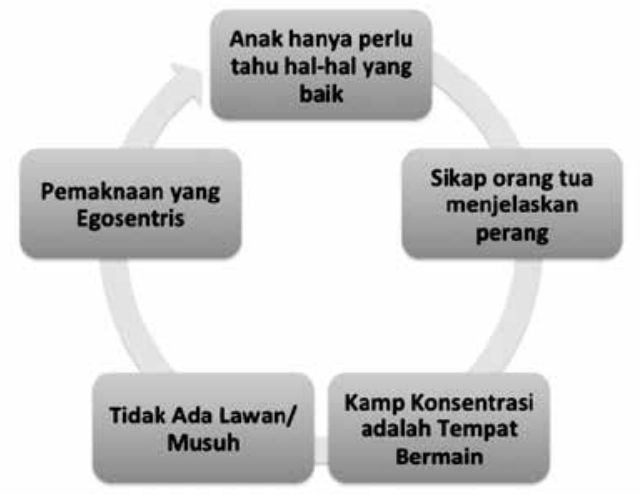

Representasi anak yang dihadirkan pada film Life is Beautiful dan The Boy in The Striped Pajamas tersebut berdasarkan pada konstruksi makna yang berhubungan dengan anak dan kondisi perang. Sikap orang tua yang enggan menjelaskan keadaan perang yang sebenarnya membuat anak memaknai setiap hal yang ditemui dalam kondisi perang dengan pemaknaannya sendiri. Pemaknaan yang ditampilkan dari kedua film tersebut antara lain kamp konsentrasi NAZI sebagai tempat bermain, tidak ada lawan atau musuh, dan pemaknaan semaunya atas baju seragam tahanan, nomor tahanan, dan kondisi kamp konsentrasi.

Representasi yang dimunculkan tersebut selaras dengan empat kategori hak anak yang dicetuskan saat Konferensi Hak Anak. Keempat hak anak tersebut adalah (1) hak kelangsungan hidup, seperti hak untuk memeroleh layanan kesehatan; (2) hak berkembang, seperti pemberian gizi dan pendidikan serta olah budaya agar anak tumbuh sebagai manusia dewasa 